\title{
Spatial distribution of G6PD deficiency variants across malaria-endemic regions
}

\author{
Rosalind E Howes ${ }^{1 *}$, Mewahyu Dewi ${ }^{2}$, Frédéric B Piel ${ }^{3}$, Wuelton M Monteiro ${ }^{4,5}$, Katherine E Battle ${ }^{1}$, Jane P Messina ${ }^{1}$, \\ Anavaj Sakuntabhai ${ }^{6}$, Ari W Satyagraha ${ }^{7}$, Thomas N Williams ${ }^{8,9}$, J Kevin Baird ${ }^{2,10}$ and Simon I Hay ${ }^{1}$
}

\begin{abstract}
Background: Primaquine is essential for malaria control and elimination since it is the only available drug preventing multiple clinical attacks by relapses of Plasmodium vivax. It is also the only therapy against the sexual stages of Plasmodium falciparum infectious to mosquitoes, and is thus useful in preventing malaria transmission. However, the difficulties of diagnosing glucose-6-phosphate dehydrogenase deficiency (G6PDd) greatly hinder primaquine's widespread use, as this common genetic disorder makes patients susceptible to potentially severe and fatal primaquine-induced haemolysis. The risk of such an outcome varies widely among G6PD gene variants.
\end{abstract}

Methods: A literature review was conducted to identify surveys of G6PD variant frequencies among representative population groups. Informative surveys were assembled into two map series: (1) those showing the relative proportions of the different variants among G6PDd individuals; and (2) those showing allele frequencies of G6PD variants based on population surveys without prior G6PDd screening.

Results: Variants showed conspicuous geographic patterns. A limited repertoire of variants was tested for across sub-Saharan Africa, which nevertheless indicated low genetic heterogeneity predominated by the G6PD A-202A mutation, though other mutations were common in western Africa. The severe G6PD Mediterranean variant was widespread across western Asia. Further east, a sharp shift in variants was identified, with high variant heterogeneity in the populations of China and the Asia-Pacific where no single variant dominated.

Conclusions: G6PD variants exhibited distinctive region-specific distributions with important primaquine policy implications. Relative homogeneity in the Americas, Africa, and western Asia contrasted sharply with the heterogeneity of variants in China, Southeast Asia and Oceania. These findings will inform rational risk assessments for primaquine in developing public health strategies for malaria control and elimination, and support the future development of regionally targeted policies. The major knowledge gaps highlighted here strongly advocate for further investigation of G6PD variant diversity and their primaquine-sensitivity phenotypes.

Keywords: Glucose-6-phosphate dehydrogenase deficiency, G6PD, Genetic variants, Spatial distribution, Primaquine, Plasmodium vivax, Malaria elimination, Haemolysis

\section{Background}

The discovery of glucose-6-phosphate dehydrogenase deficiency (G6PDd) occurred during the clinical development of primaquine against the relapse of Plasmodium vivax malaria in American prisoner volunteers during and immediately after the Second World War [1]. The high prevalence of this inherited disorder among people at risk

\footnotetext{
* Correspondence: rosalind.howes@zoo.ox.ac.uk

'Spatial Ecology and Epidemiology Group, Department of Zoology,

University of Oxford, South Parks Road, Oxford, UK

Full list of author information is available at the end of the article
}

of malaria [2], along with the practical difficulty of its diagnosis where almost all of them live [3], sharply limits the otherwise enormous public health importance and utility of primaquine in controlling and eliminating malaria [4-8]. This drug is currently the only licensed therapy active against the latent liver-stages of $P$. vivax responsible for multiple relapses in the weeks, months, and several years following a single infectious bite by an anopheline mosquito [9]. As with the primary infection, and despite the long-held dogma that considered vivax malaria clinically benign, each relapse carries risk of severe disease and 
mortality [5]. Furthermore, primaquine is the only drug with activity against the mature transmission-stages of all Plasmodium species $[4,10,11]$, giving it a role of undeniable importance in reducing transmission levels, most particularly in preventing the spread of artemisinin-resistant Plasmodium falciparum [12-15]. The recently published model-based geostatistical mapping study showed that G6PDd is prevalent across malaria-endemic countries, with an estimated median allele frequency in these regions of $8.0 \%$ (50\% CI: 7.4-8.8) [2], thought to be driven by a selective advantage against life-threatening malaria [16-18]. Despite its prevalence and hindrance to malaria control, the spatial patterns of the genetically and clinically diverse G6PD mutations are poorly documented globally; this knowledge gap, highlighted by others [19], constitutes the focus of the present study. A better understanding of the spatial epidemiology of G6PD gene variants would support assessments towards safe delivery strategies to increase access to primaquine.

G6PD enzyme generates nicotinamide adenine dinucleotide phosphate (NADPH), which represents the primary defence against oxidative stresses in red blood cells (RBC). Mutations in the G6PD gene can destabilize the enzyme and reduce its activity levels, leaving cells vulnerable to damage from exogenous triggers, including certain foods, infections, and a range of drugs, that may lead to RBC lysis and acute haemolytic anaemia (AHA) $[20,21]$. The clinical burden of G6PDd was evaluated in the Global Burden of Disease Study 2010 [22,23], and includes a range of pathologies, notably neonatal jaundice and AHA. The clinical symptoms due to primaquineinduced haemolysis range from negligible to lethal $[24,25]$ depending largely upon the variants involved and drug dosing.

At least 186 mutations have been characterized in the G6PD gene [26], although not all are polymorphic and of clinical significance. G6PD variants have been categorized into three types (Table 1) [21,25]. About half of the known variants appear to be sporadic mutations identified in only a handful of patients [27]. These rare variants, classified as Type 1, usually express very severe chronic disease - a pathology known as chronic nonspherocytic haemolytic anaemia (CNSHA) - which can result in lifelong dependency on blood transfusion [25].
Although numerous by type, these variants never reach polymorphic frequencies (prevalence $\geq 1 \%$ ) and are thus not of serious public health concern. Type 2 variants, in contrast, do reach frequencies $\geq 1 \%$ and put individuals at significant risk of haemolytic crises. These Type 2 variants correspond to the Class II and III variants of the WHO-endorsed classification system [28,29]. Given their public health significance, being both polymorphic and clinically significant, Type 2 variants are the focus of the present study. Type 3 variants express phenotypically normal G6PD activity and present no clinical or public health concerns.

The G6PD $A$ - variant from Africa has been the most thoroughly studied with respect to sensitivity to primaquine. This may be a consequence of being the first studied and the most accessible (in African American volunteers) during primaquine development [30]. This variant typically exhibits residual enzyme activity of about $5-10 \%$ of normal levels [31]. Primaquine toxicity in the G6PD $A$-volunteers was relatively mild and selflimiting [32]; G6PD $A$ - individuals dosed with daily primaquine for four months have been observed to typically recover from relatively shallow AHA within about three weeks, despite continued daily dosing [33]. In contrast, the G6PD Mediterranean variant, which is common across southern Italy (particularly Sardinia) and the Arabian Peninsula [34], exhibits exceedingly low residual enzyme activity $(<1 \%$ [35]) and predisposes individuals to favism [36,37] and clinically severe AHA following primaquine therapy [12,35,38,39]. G6PD Mahi$\mathrm{dol}$ is the best-characterized Asian variant and is considered predominant across Myanmar and Thailand $[40,41]$. Enzyme activity in G6PD Mahidol individuals is reduced to $5-32 \%$ of normal levels [42], and its primaquine sensitivity phenotype lies between that of the G6PD $A$ - and Mediterranean variants [43,44]. As for the balance of many dozens of other G6PD variants, residual enzyme activity is generally known for many [26], but the primaquine sensitivity phenotypes for any of these remains effectively unknown [4]. There may be an inverse correlation between residual enzyme activity and AHA sensitivity to primaquine (as roughly seen with the three variants discussed), but this is not yet firmly established.

\section{Table 1 G6PDd variant types}

\begin{tabular}{|c|c|c|c|c|}
\hline Type & Residual enzyme activity & Population-level prevalence & Clinical significance & $\begin{array}{l}\text { Primaquine-associated public } \\
\text { health concern }\end{array}$ \\
\hline Type 1 & $<10 \%$ & Sporadic (never polymorphic) & Severe and chronic: CNSHA & None - too rare \\
\hline Type $2^{\S}$ & $<1-50 \%$ & Polymorphic & $\begin{array}{l}\text { Asymptomatic until exposed to } \\
\text { an exogenous trigger }\end{array}$ & $\begin{array}{l}\text { Yes - commonly inherited and cause } \\
\text { individuals to be at risk of haemolysis }\end{array}$ \\
\hline Type 3 & Normal (>50\%) & Polymorphic (wild-type) & None & None - G6PD normal \\
\hline
\end{tabular}

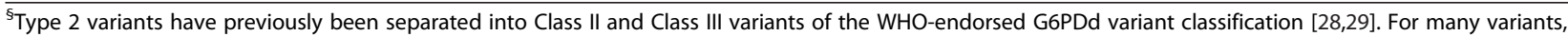
however, this subdivision is blurred and poorly defined [25]. 
The diversity of G6PDd phenotypes and genotypes, and our limited knowledge thereof, greatly compounds the difficulty of addressing the technical and practical limitations which this deficiency imposes on primaquine treatment for attacking the endemic malarias [45]. National authorities responsible for the prevention, control and treatment of endemic malaria naturally strive for evidence-based practices that minimize risk and maximize benefit. The complexity of the problem imposed by G6PDd - both by its genetic variability and its heterogeneous prevalence [2] - compounds the difficulty of developing practical and useful tools for assessing risk and benefit. The present study begins the task of characterizing G6PD variant spatial distribution and diversity, with the aim of contributing towards the evidence-based policies for primaquine treatment so essential to realizing the vision of malaria elimination.

\section{Methods}

The aim of this study was to map population surveys reporting the prevalence of the G6PD variants of greatest public health significance. A systematic literature review was conducted of online biomedical databases for all records referring to "G6PD" or "glucose-6-phosphate dehydrogenase" and then cross-referenced with previously published G6PD variant databases [26,46-50]. The study was limited to data from malaria-endemic countries $[2,51,52]$, corresponding to where primaquine therapy is needed. Refer to Additional file 1 for more detailed descriptions of the methodology. The assembled datasets are available from the authors on request.

\section{Survey inclusion criteria}

The assembled library of sources was reviewed for population surveys of G6PD variants and those meeting a specific set of inclusion criteria (Figure 1) were identified. First, only surveys that could be geopositioned to at least the national level were included, and these were mapped to the highest spatial resolution available, ideally as point locations (e g, villages). Second, to ensure that survey samples were widely representative of the communities being studied, only surveys which provided apparently unbiased prevalence estimates were included: all case studies and patient groups, malaria patients (to avoid underestimating frequencies of G6PD variants which may provide a protective effect against malaria), family studies, and samples selected according to ethnic background were therefore excluded. Third, only surveys using molecular diagnostics were included to avoid the diagnostic uncertainty of surveys reliant on biochemical methods (see Additional file 1).

Surveys meeting these criteria were of two types depending upon the nature of the population samples surveyed and were mapped as two separate series:

\section{Map series 1: variant proportion maps}

Studies examining individuals who had been previously identified as phenotypically G6PDd from a population screening survey and were being followed-up for molecular diagnosis of underlying mutations were included in map series 1 . Pie charts were chosen to display the relative proportions of the different variants identified in each of the surveys, with each colour-coded segment proportional to the variant's relative frequency across the study sample. Sample size was reflected in the relative sizes of the pie charts, which was transformed on a square-root scale to allow clear visualization.

It is important to note that studies did not always attempt to identify all the variants represented in the legends of the maps. For instance, if only G6PD Mediterranean was tested for among a sample of deficient individuals, those individuals who tested negative would be included in the "Other" category, regardless of whether they expressed one of the other variants listed in the legend or a completely different one. The absence of a specific variant from a sample can only be inferred if no "Other" samples are reported.

\section{Map series 2: allele frequency maps}

Surveys which investigated G6PD variants in crosssectional population samples without prior phenotype screening were included in map series 2 . These studies estimated the allele frequencies of selected G6PD variants at the population level and were mapped spatially using bar charts to represent the allele frequencies. This visualization conveyed the important concept that frequency estimates are only available for variants that were included in the diagnoses, underlining the importance of knowing which variants had been tested for. The variants tested for were named in the vertical bars of the bar charts. Empty spaces along the $x$-axis indicate that the named variant was tested for but not identified in the population sample. The size of the plots meant that in some cases, significant spatial uncertainty was introduced to their positioning on the map (Additional file 1).

The G6PD gene's X-linked inheritance means that allele frequencies correspond to frequencies among males. Heterozygous inheritance in females makes allele frequency estimates from female samples harder to calculate confidently as not all studies consistently distinguished heterozygotes from homozygotes. For reliability, therefore, only data from males were included in these variant allele frequency maps.

\section{Variant inclusion criteria}

Given the diversity of G6PD variants, for the purposes of this mapping study it was necessary to identify those variants that presented a primary public health concern. This study focussed on Type 2 variants which (i) express 


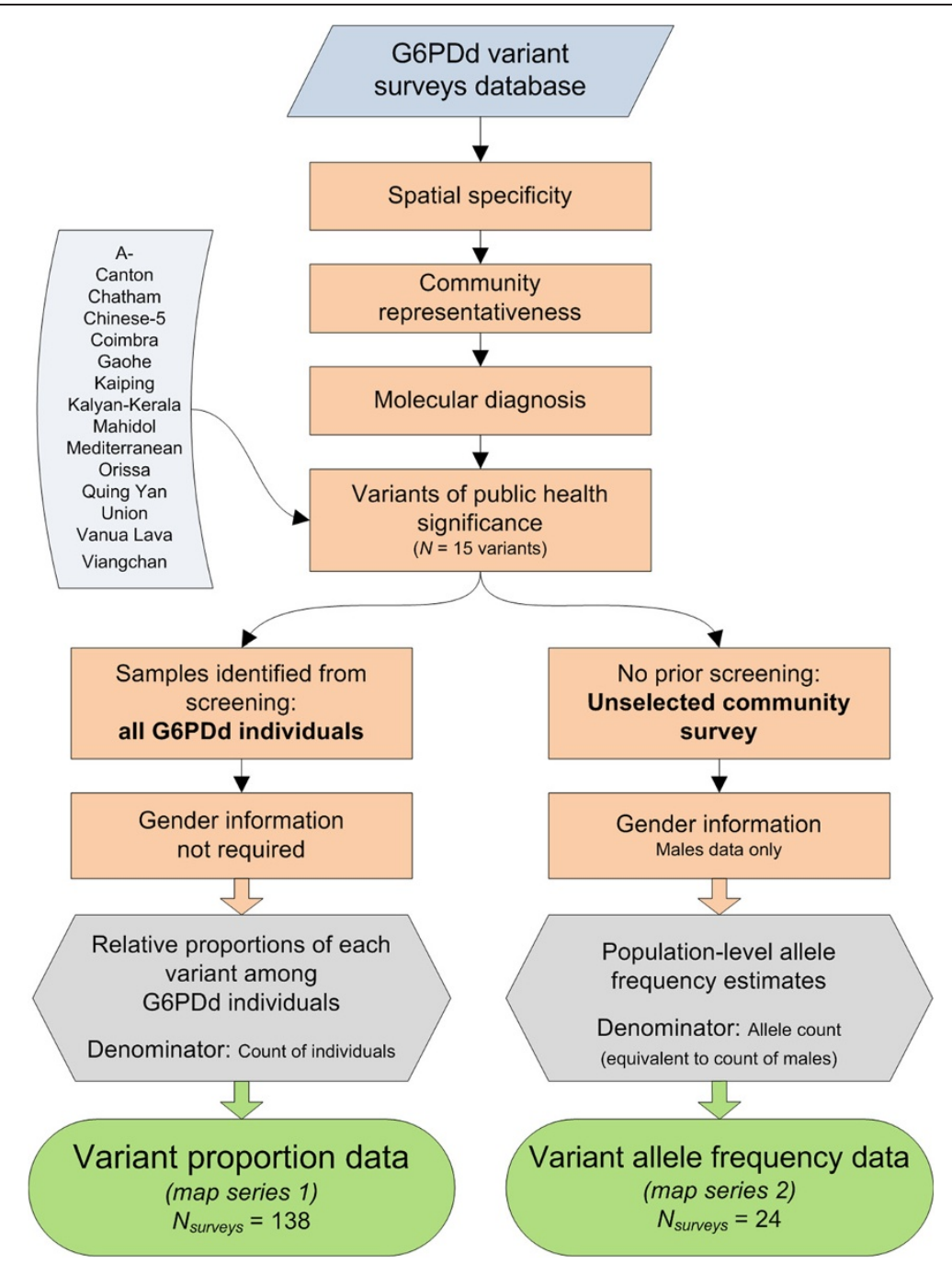

Figure 1 Survey inclusion criteria and G6PDd variant map outputs. Orange rectangles indicate the exclusion criteria, grey hexagons summarize the two final input data, and green rods represent the two map types.

significantly reduced enzyme activity $(<50 \%)$; (ii) are clinically significant by predisposing individuals to haemolytic anaemia; and, (iii) reach polymorphic allele frequencies at the population level (Table 1). Although 77 Type 2 variants have so far been described [26], the database of population survey data compiled in this study indicated that most variants were reported fewer than ten times (most fewer than three) and, when identified, were found to have low prevalence. A clear subset of variants was responsible for the majority of investigated G6PDd cases (Additional file 1); these were defined for the purposes of this study to be those variants reported from a minimum of ten localities across the malaria-endemic region. This ensured that the spatial distributions of the most significant variants could be legibly visualized in the maps. Fifteen variants met these criteria: G6PD A-, Canton, Chatham, Chinese-5, Coimbra,
Gaohe, Kaiping, Kalyan-Kerala, Mahidol, Mediterranean, Orissa, Quing Yan, Union, Vanua Lava, and Viangchan (Figure 1).

\section{Results}

\section{The database}

A total of 18,939 bibliographic sources were identified from keyword searches, of which 2,176 were considered likely to include spatial information about G6PD variants. Following their detailed review, 93 published and unpublished sources were identified which reported surveys eligible for inclusion in the maps (listed in the Additional file 2). From these sources (which could each report several surveys from multiple locations), 138 population surveys could be geolocated and met the criteria for map series 1 , as these were of community samples which had undergone prior screening for phenotypic 
G6PDd. Map series 2 was populated with 24 geolocated population surveys of community samples providing variant frequency estimates. Map series 1 data were predominantly from populations in Asia (123/138 surveys; $89 \%$ ), while map series 2 data were almost exclusively from the Africa + region (Africa, Yemen and Saudi Arabia [53]: 20/24 surveys, or $83 \%$ ). These database descriptors are summarized in Table 2.

\section{Distribution of G6PD variants in malaria-endemic regions}

The maps reveal conspicuous distinct geographical patterns in the distribution and prevalence of G6PD variants across regions. The two series of maps represent both the relative proportions of the variants responsible for phenotypic G6PD enzyme deficiency (Figures 2, 3, 4, $5,6,7)$ and the allele frequencies of selected variants (Figure 8 and Additional files 3, 4 and 5). Together, these maps revealed a number of clear patterns further described below: (i) a relatively low diversity of G6PD variants reported from populations of the Americas and Africa + regions, among whom variants of the G6PD Aphenotype are predominantly searched for and reported; similarly, G6PD Mediterranean was predominant in west Asia (from Saudi Arabia and Turkey to India); (ii) a sharp shift in variants identified east of India, showing no admixture with the common variants of west Asia; (iii) high variant diversity in east Asia and the AsiaPacific region, with multiple variants co-occurring and no single variant being predominant.

\section{G6PD variants in the Americas}

Relatively few surveys were available from the Americas (nine in map series 1 , one in map series 2). Figure $2 \mathrm{~A}$ indicates that among G6PDd individuals, the predominant variant was G6PD $A$ - (in the majority of cases encoded by the G6PD $A-{ }^{202 A}$ mutation, though the G6PD $A-{ }^{968 C}$ variant was common in some samples), identified in $91 \%$ of deficient individuals surveyed across the region (579 of 636 total G6PDd individuals

Table 2 Summary of input data according to map type

\begin{tabular}{llllll}
\hline & & \multicolumn{2}{c}{$\begin{array}{c}\text { Africa+ } \\
\text { (Malaria-endemic countries only) }\end{array}$} \\
\hline $\begin{array}{llllll}\text { Map series 1 Variant } \\
\text { proportion maps }\end{array}$ & $N_{\text {surveys }}$ & 6 & 9 & 123 & 138 \\
& $N_{\text {countries }}$ & 5 & 4 & 16 & 25 \\
& $N_{\text {G6PDd indivs }}$ & 258 & 636 & 5,278 & 6,172 \\
& Mean & 43 & 71 & 43 & 45 \\
& sample size & & & & \\
Map series 2 Variant & $N_{\text {surveys }}$ & 20 & 1 & 3 & 24 \\
frequency maps & $N_{\text {countries }}$ & 13 & 1 & 2 & 16 \\
& $N_{\text {male indivs }}$ & 6,796 & 509 & 448 & 7,753 \\
& Mean & 340 & 509 & 149 & 323 \\
& sample size & & & & \\
\hline
\end{tabular}

surveyed). Other variants identified included G6PD Med-

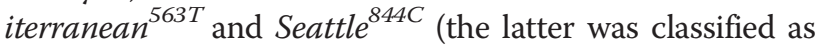
part of the "Other" category as it was only reported twice, both instances from Brazil where it reached a prevalence of $13 \%(n=2 / 15$, [Additional file 2: S63] and 5\% $(n=9 /$ 196, [S30])). A survey of Mexicans reported $61 \%$ of deficient cases being due to various G6PD $A$-variants, but did not test for any other variant (e g, G6PD Mediterranean), explaining the large proportion of "Other" variants [Additional file 2: S85].

A single community screening survey could be identified which investigated G6PD variant allele frequencies. This was in Acrelândia, Brazil, and searched for only one single-nucleotide polymorphism (SNP): G6PD $A_{-}{ }^{202 A}$. An allele frequency of $6 \%(\mathrm{n}=509$, [Additional file 2: S14]) was reported (see Additional file 3).

G6PD variants in Africa, Yemen and Saudi Arabia (Africa+) Very few studies $(n=6)$ investigating the variants of known G6PDd individuals were identified from the Africa + region (Figure 3). Where available, both in West Africa and the western Indian Ocean islands, surveys indicated G6PD $A_{-}{ }^{202 A}$ to be the predominant variant; in Saudi Arabia, the G6PD Mediterranean variant was responsible for $78 \%$ of G6PDd cases in two surveys in the western coastal city of Jeddah [Additional file 2: S6,S28].

Surveys investigating population-level frequencies of specific G6PD variants were more common (Figure 8 and Additional file 4). These consistently looked for SNPs of G6PD A-, notably focussed on the G6PD $A_{-}^{-202}$ locus. Frequencies of this SNP were over $20 \%$ in surveys from Nigeria and Côte d'Ivoire in West Africa, and found at $19 \%$ in coastal Kenyan populations. The G6PD $A-{ }^{968 C}$ mutation encodes a similar phenotype to G6PD $A-{ }^{202 A}$ and was found to be the more common of the two in West African populations (in The Gambia and Senegal, for instance [Additional file 2: S21,S25]); despite this, only six of 20 surveys across Africa + included the G6PD $A^{-968}$ SNP in their diagnoses. Large population surveys in East Africa ( $\mathrm{n}=311$ in Uganda [Additional file 2: S38] and $\mathrm{n}=2,756$ in Kenya [Additional file 2: S76]) found no evidence of the G6PD $A-{ }^{968 C}$ mutation despite frequencies of 12 and $19 \%$ of the G6PD $A-^{202 A}$ mutation, respectively.

Most population surveys $(70 \%)$ in the Africa + region tested the G6PD $A-{ }^{376}$ locus. Although this mutation has barely any clinical effect, it is commonly co-inherited with mutations at other loci, together encoding the range of G6PD $A$ - variants (Figure 8). The G6PD $A-{ }^{376 G}$ variant had very high prevalence among sub-Saharan African populations, and in all cases affected over $10 \%$ of individuals surveyed; further, in a subset of ten out of 16 of these surveys, its frequency reached 25-50\%. Exceptions to this high G6PD $A^{376 G}$ prevalence were 


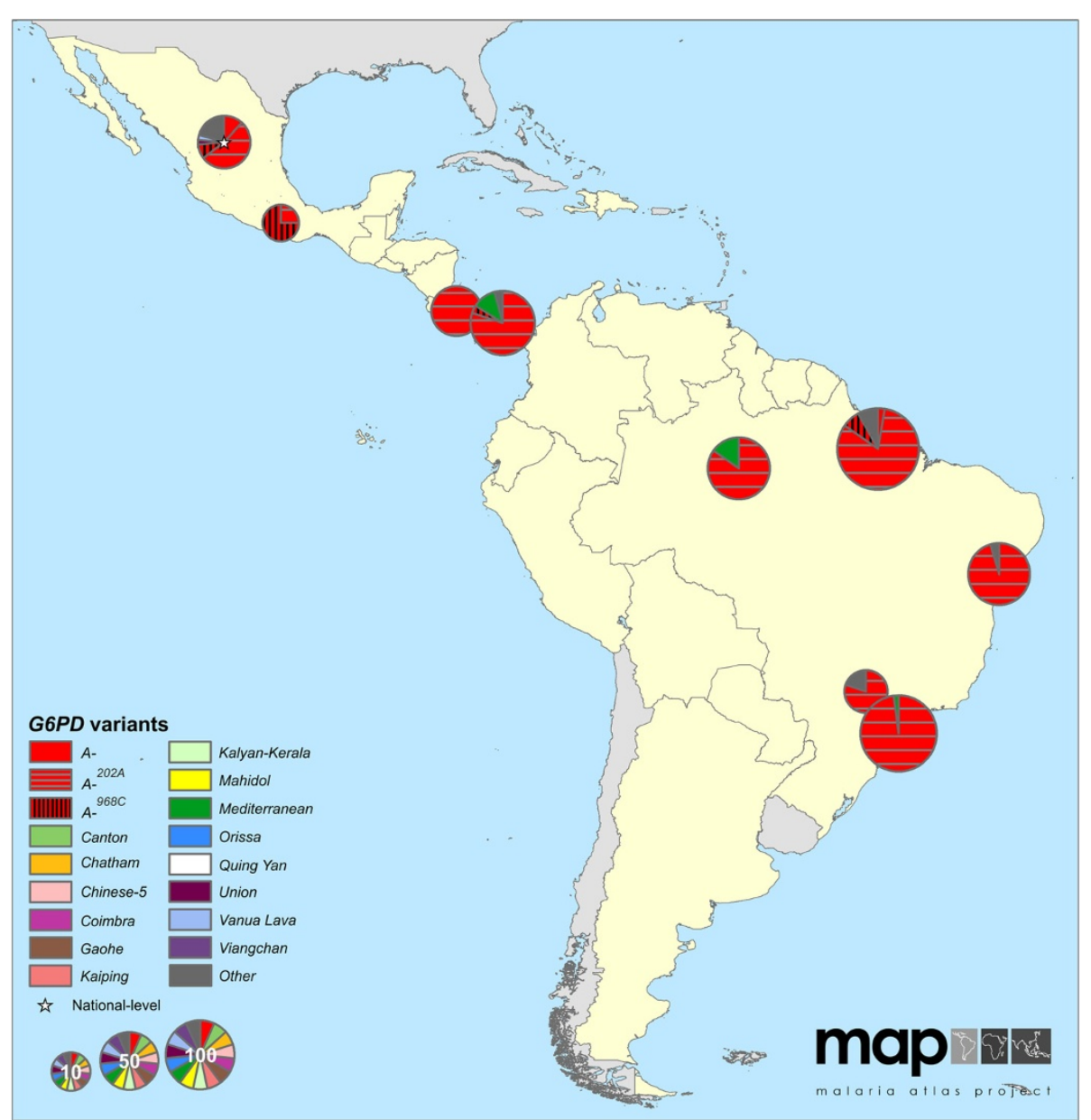

Figure 2 G6PDd variant proportion map: Americas (map series 1). Map includes nine surveys with a mean sample size of 71 (range: 8-196); one survey was mapped at the national level. Pie charts represent individuals previously identified as G6PDd. Sample size is reflected in the size of the pie charts, which is transformed for clarity on a square-root scale. Surveys which could only be mapped to the country-level are indicated by a white star; this applied to seven surveys globally. Spatial duplicates from independent studies were mapped with a "jitter" of 0.5-1 decimal degrees in their latitude or longitude coordinates to allow visualization of the multiple charts. Malaria-endemic countries in the region mapped are shown with a yellow background; white backgrounds indicate endemic countries outside the region in focus; grey backgrounds represent malaria-free countries. G6PDd variants that could not be diagnosed were reported as "Other".

two surveys ( $\mathrm{n}=46$ and 55) from northern Sudan, which reported low $(<5 \%)$ prevalence [Additional file 2: S41]; the G6PD $A^{202 A}$ mutation was not detected in these samples.

\section{G6PD variants in Asia and Asia-Pacific}

Greatest $G 6 P D$ variant diversity globally was across the Asia and Asia-Pacific regions (Figures 4, 5, 6, 7) where up to ten variants were reported to co-occur within single populations. Furthermore, significant proportions of "Other" cases were frequently reported in the variant proportion maps (map series 1), indicating that genetic diversity is greater than represented by the pie charts in these maps.

From Turkey to Pakistan (Figure 5), G6PD Mediterranean was predominant, identified in 728 of 895 G6PDd indivi- duals examined (81\%). Two variants, G6PD KalyanKerala $^{949 A}$ and Orissa ${ }^{131 G}$, were reported exclusively from Indian populations. On the Indian sub-continent, these two variants and the G6PD Mediterranean variant represented the majority ( $88 \%$ of $\mathrm{n}=555$ G6PDd individuals tested) of deficiency cases, though notable proportions (up to $80 \%$ ) of "Other" cases were also reported from eastern and southern India.

East of India, a completely different set of variants emerged (Figure 6). G6PD Mahidol ${ }^{487 A}$ predominated across Myanmar, with 98 of 117 G6PDd individuals (84\%) diagnosed across 14 locations as carrying this variant. Variants common among G6PDd individuals in southeast China were largely unique to these populations. Of the 2,883 G6PDd cases from China, the commonly diagnosed variants included G6PD Kaiping ${ }^{1388 A}$ 


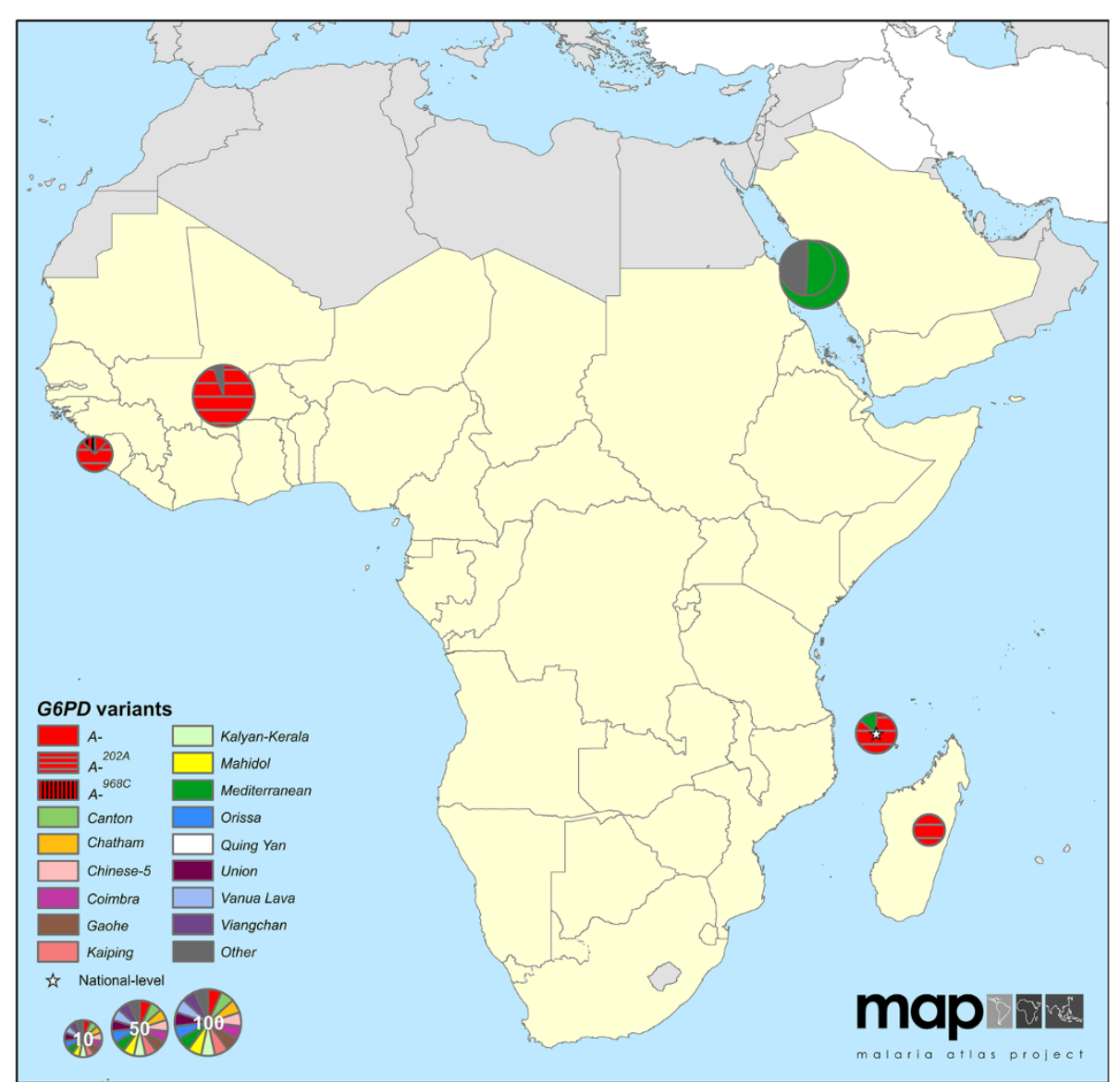

Figure 3 G6PDd variant proportion map: Africa+ (map series 1). Map includes six surveys with a mean sample size of 43 (range: 5-110). One survey was mapped at the national level. (See Figure 2 for full legend).

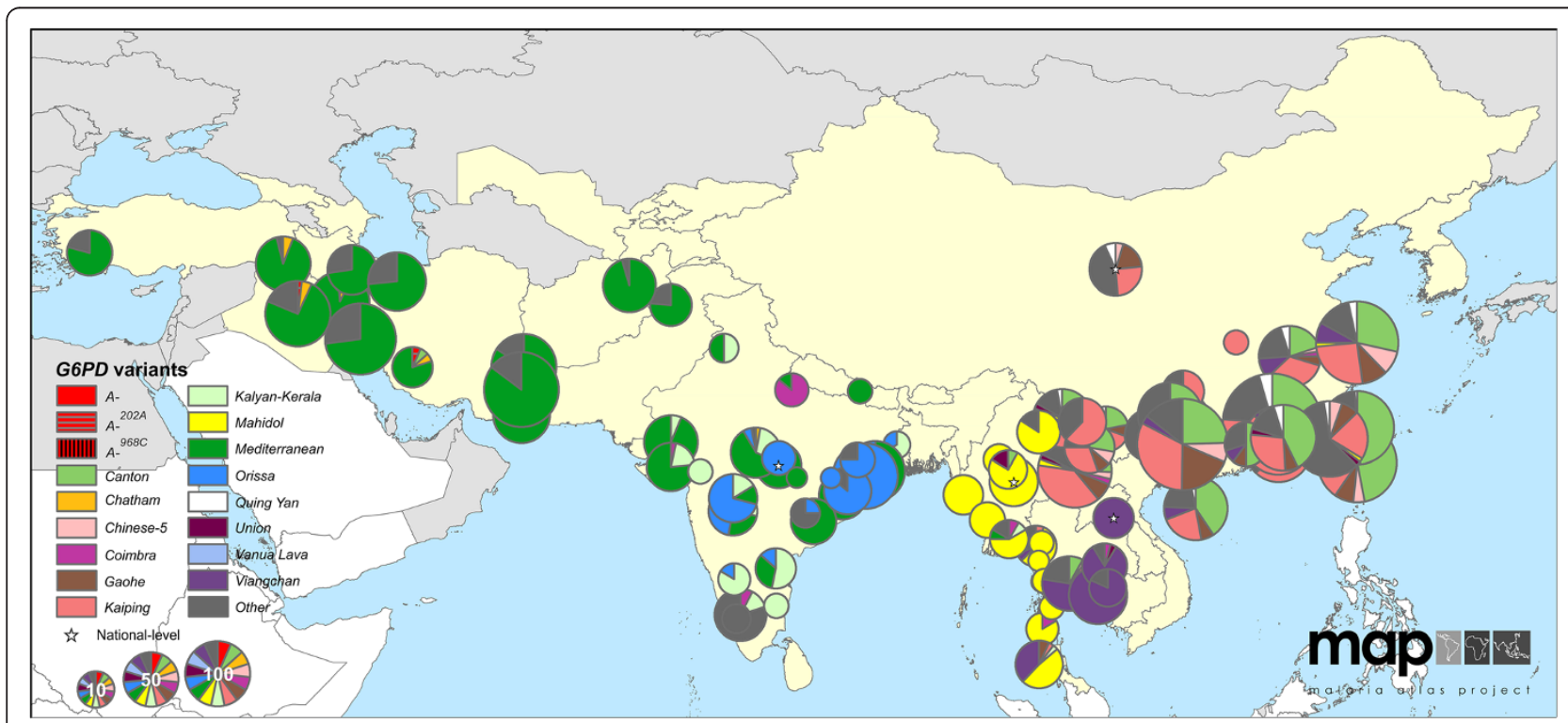

Figure 4 G6PDd variant proportion map: Asia (map series 1). Map includes 87 surveys with a mean sample size of 53 (range: 1-532). Four surveys were mapped to the national level. (See Figure 2 for full legend). 


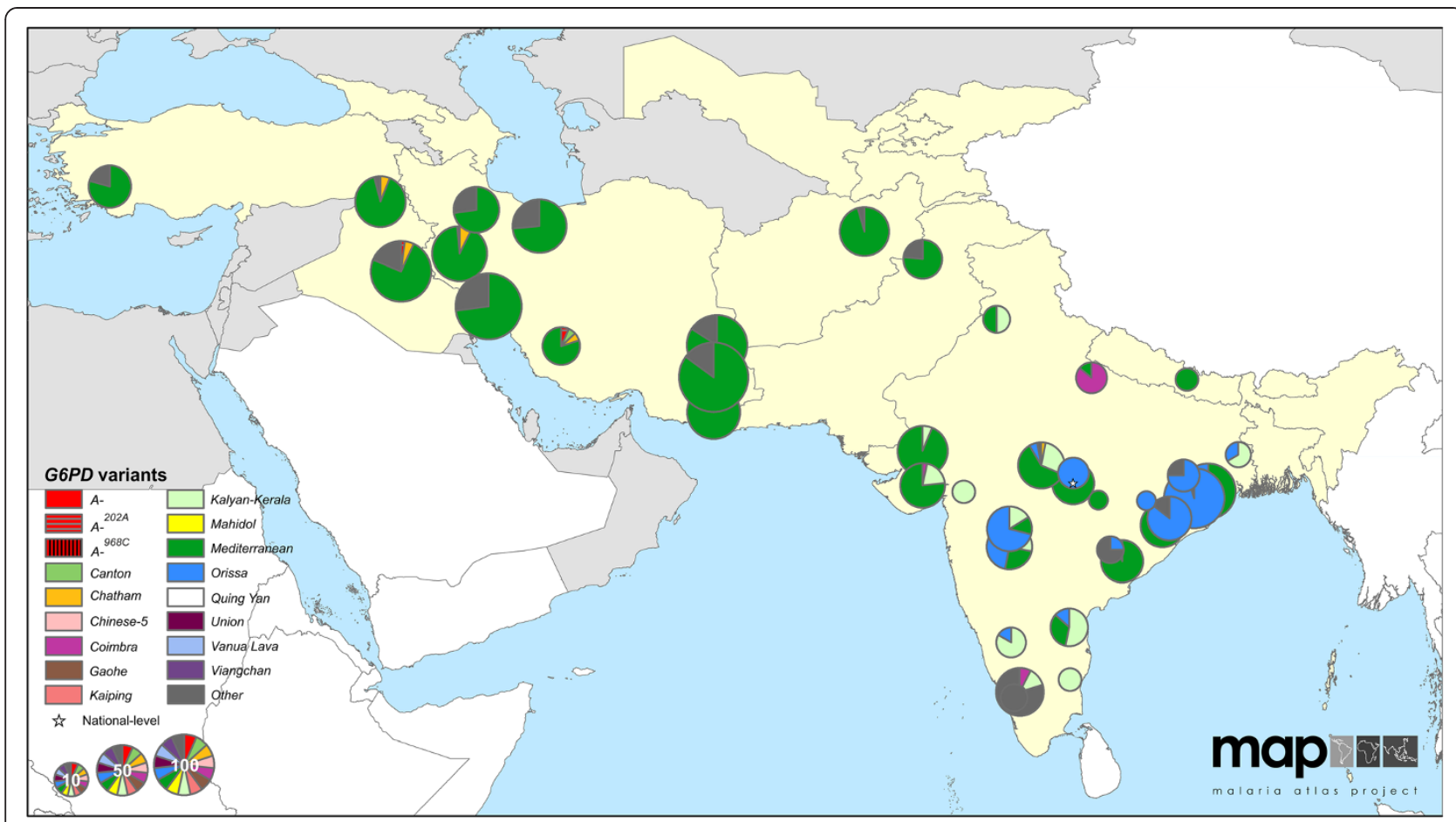

Figure 5 G6PDd variant proportion map: West Asia (map series 1). A higher resolution map of Figure 4.

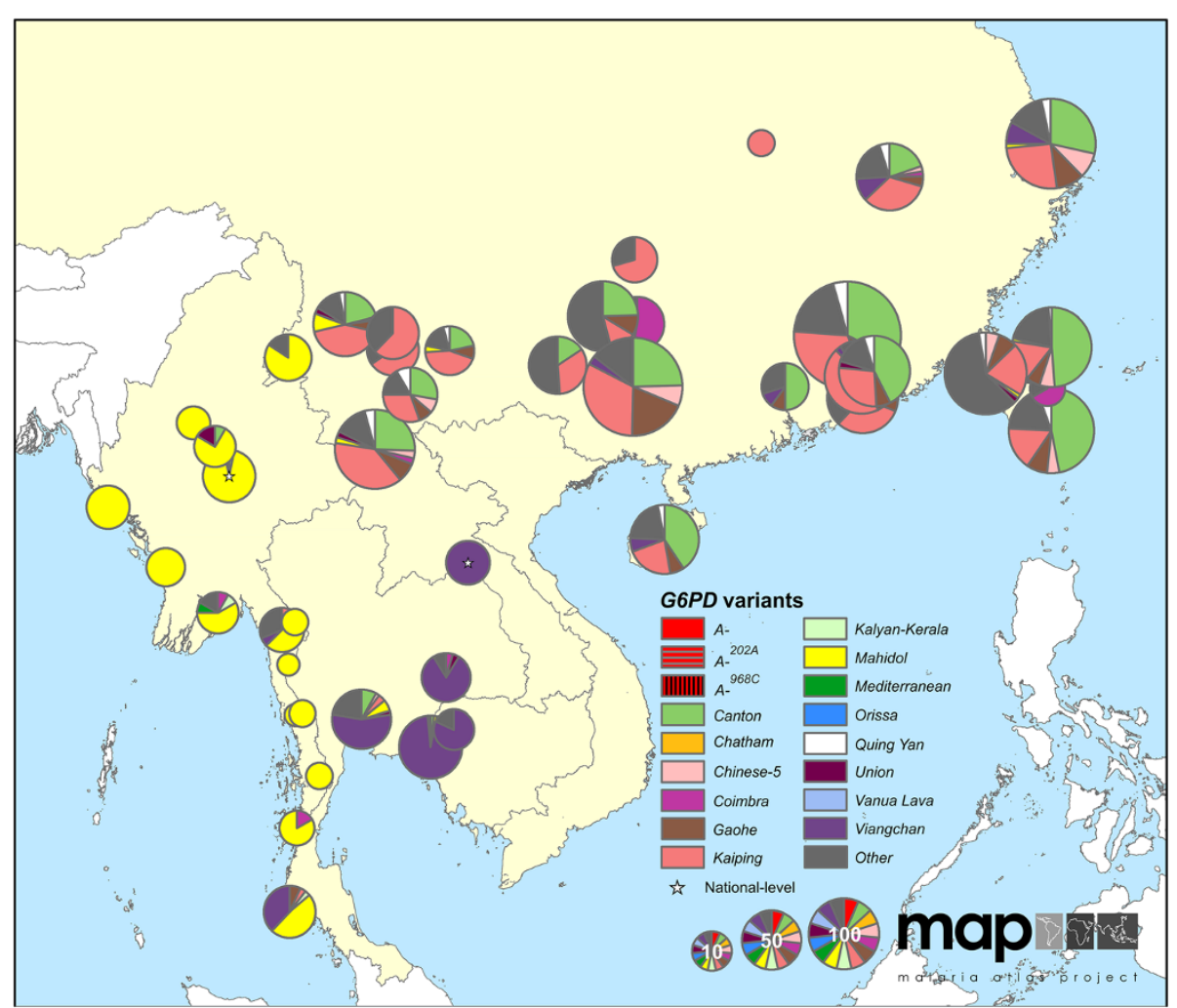

Figure 6 G6PDd variant proportion map: East Asia (map series 1). A higher resolution map of Figure 4. 


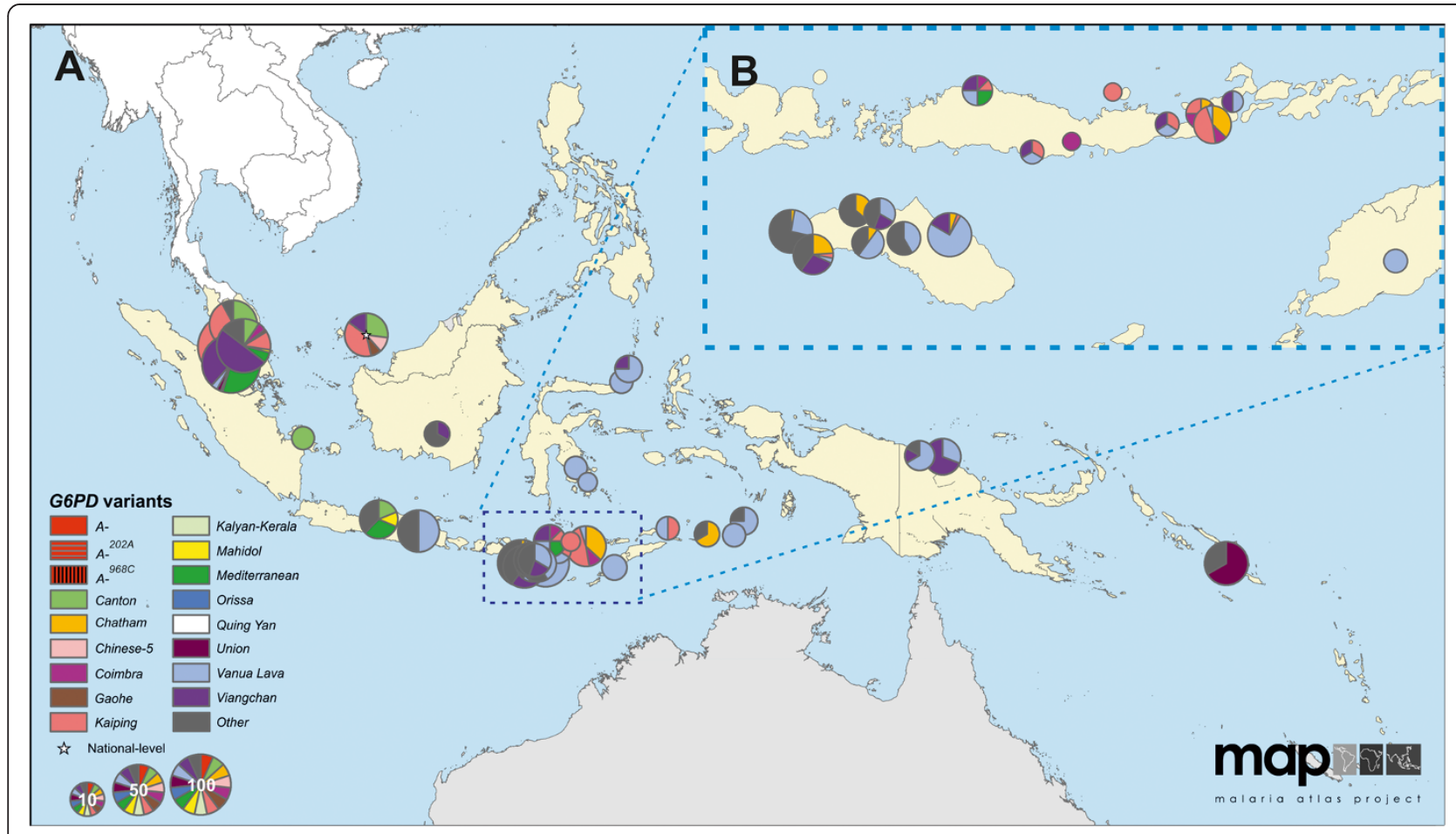

Figure 7 G6PDd variant proportion map: Asia-Pacific (map series 1). Panel A show the full map, which includes 36 surveys with a mean sample size of 18 (range: 1-128). One survey was mapped at the national level. The East Nusa Tenggara province islands identified by the dotted box are shown at higher resolution in Panel B. (See Figure 2 for full legend).

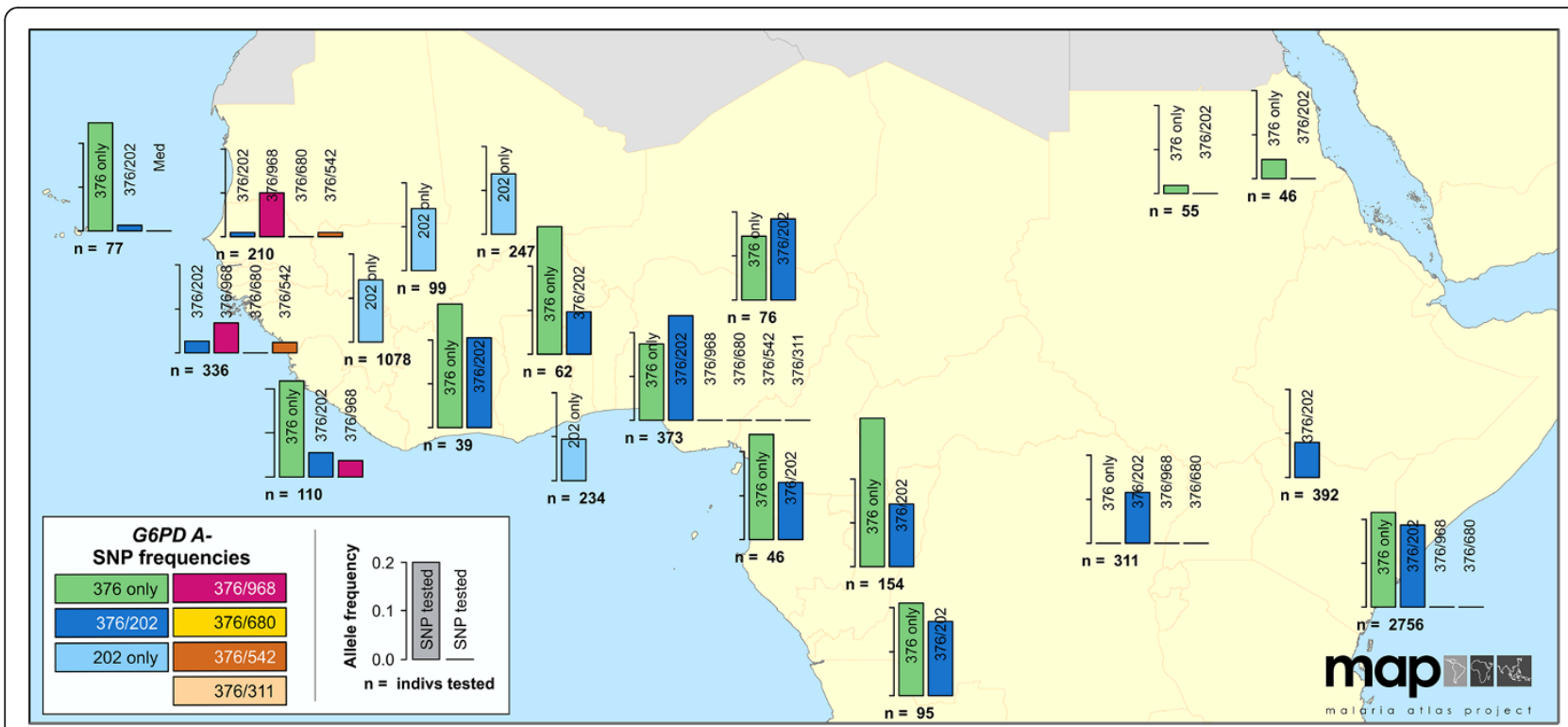

Figure 8 G6PD A- variant SNP frequency map for Africa (map series 2). Bar charts representing the frequencies of G6PD variants. The variants that were tested for in each location are listed above the $x$-axis. Empty spaces along the $x$-axis indicate that the named variant was tested for but not identified in the population sample. Survey locations are mapped to closest approximation at the point of origin of the plots and exact locations shown in Additional file 4. Sample size is listed under each plot. Equivalent maps of the Americas and Asia are Additional files 3 and 5 . 
(total G6PDd cases: 827; 29\% across China), Canton ${ }^{1376 T}$ (792 cases; 27\%), Gaohe ${ }^{95 G}$ (265 cases; 9\%), Chinese- $5^{1024 T}$ (104 cases; 4\%) and Quing Yan $^{392 T}$ (87 cases; 3\%). The distribution of G6PD Viangchan ${ }^{871 A}$ was diffuse, reportedly common from Laos (where examination of 15 G6PDd individuals all carried this variant [Additional file 2: S34]) and Cambodia (reported from 61 out of 64 G6PDd individuals [Additional file 2: S43]) to Papua New Guinea (where a sample of 13 G6PDd individuals included nine with this variant [Additional file 2: S33]).

Variants across the Asia-Pacific region were also highly heterogeneous (Figure 7). The common pattern emerging from the 36 surveys of deficient individuals identified from this region $\left(n_{\text {indivs }}=635\right)$ was the diversity of variants and the heterogeneity of their prevalence among different populations. Furthermore, it should be noted that 20 of these surveys tested fewer than ten G6PDd individuals, limiting the diversity that would be captured and thus the representativeness of these reports. The greatest diversity identified in a single survey was from the Malaysian neonatal screening programme in Kuala Lumpur, which recorded ten variants from an investigation of 86 G6PDd newborns [Additional file 2: S4]. The short spatial-scale heterogeneity of this co-occurring variant diversity is illustrated by a set of surveys across the East Nusa Tenggara province of Indonesia (Figure 7B). Amid this co-occurring variant heterogeneity, the G6PD Vanua Lava ${ }^{383 C}$ variant was the most common variant reported from Indonesian studies (identified in 84 out of 249 G6PDd individuals tested).

Only three allele frequency surveys (map series 2) could be identified from the Asia region (of 24 globally) [Additional file 2: S66,S83]. G6PD Mahidol was most commonly tested for, with allele frequencies of $12 \%$ and $18 \%\left(\mathrm{n}_{\text {tested }}=353\right.$ and 11, respectively; Additional file 5). Two surveys in Thailand tested for a broader range of variants; one found five variants (G6PD Canton, Kaiping, Mahidol, Union and Viangchan; $\mathrm{n}_{\text {tested }}=84$ ) at allele frequencies of $1-2 \%$; and the other, with a smaller sample size $\left(n_{\text {tested }}=11\right)$, identified only the G6PD Mahidol variant [Additional file 2: S66].

\section{Discussion}

Over a third of the world's population lives at risk of $P$. vivax infection [14,52,54]. Limited evidence underpins estimates of clinical cases, but these have been estimated at 70-400 million annually [55,56], including potentially severe illness and death $[5,24,57,58]$. In the context of malaria elimination, therapy must target all infections, including asymptomatic and submicroscopic blood-stage infections, dormant liver-stage hypnozoites as well as clinical cases $[59,60]$. One of the many consequences of a half-century of neglect of $P$. vivax has been the failure to address the primaquine toxicity problem with G6PDd and thereby solve the real problem of lack of access to primaquine for almost all malaria patients. No non-toxic therapeutic alternatives exist, and existing G6PDd diagnostics are largely impractical in point-of-care settings $[4,6,21,45,56]$.

Fear of harm also leads to avoidance of primaquine as a $P$. falciparum transmission-blocking agent. The single transmission-blocking $0.75 \mathrm{mg} / \mathrm{kg}$ dose, consistently inconsequential in G6PD $A$ - volunteers, reliably caused $20-30 \%$ drops in haematocrit in healthy Europeans with G6PD Mediterranean [39]. This risk, acknowledged at least 30 years ago, was only acted upon in 2012 with the WHO offering a recommendation for a lower dose of primaquine $(0.25 \mathrm{mg} / \mathrm{kg})$ gametocytocide alongside $P$. falciparum blood schizontocidal treatment with no requirement for prior G6PDd testing [10,11,61-63]. Nonetheless, many nations, in particular in Africa where there has been an almost complete lack of experience with primaquine [61] and where G6PDd prevalence is commonly greater than $10 \%$ [2], still resist use of this drug. An understanding of the therapeutic risks from primaquine in relation to the $G 6 P D$ variants predominant in each region will contribute to the body of evidence on which to base policy.

Access to safe therapy either requires an alternative non-haemolytic drug or a practical means to identify G6PDd $P$. vivax malaria patients in remote, impoverished sites. Neither is likely in the short-term and improved use of primaquine promises immediately applicable and useful prospects [21]. This aim demands refined knowledge of the spatial epidemiology and primaquine-sensitivity phenotypes of G6PD variants. Development of primaquine treatment strategy could exploit, for example, the total dose effect (whereby therapeutic efficacy is dependent upon the total drug dose irrespective of the regimen duration [64-66]), to tailor population/region-specific dosing parameterized according to the highest dose safely tolerated by individuals with the most vulnerable local G6PD variant.

\section{G6PD variants in Africa}

The G6PDd phenotype has long been considered homogenous across African populations, with much of the pre-molecular era literature reporting G6PD $A$ - from electrophoresis assays across the continent [34]. The early investigations of "primaquine sensitivity" among G6PD $A$ - volunteers found primaquine-induced haemolysis to be mild and self-limiting [1,30,64,67-69]. Nevertheless, the haemolytic susceptibility of this "mild" variant has been observed through severe reactions requiring transfusion [70], as well as through the failure of the Lapdap (chlorproguanil-dapsone) anti-malarial trials [71,72], and as haemolysis induced by the ingestion of fava beans [73], a pathology previously thought to only be triggered by more severe variants [74]. Haemolysis associated with 
G6PD $A$-, while perhaps less severe than with other variants in some circumstances or settings, ought not be universally characterized as "mild" as this risks leading to misplaced confidence in a relatively cavalier application of the drug.

Molecular analyses of G6PD variants among Africans revealed a diversity of SNPs within the umbrella of the G6PD A- phenotype [75]. The data, here mapped spatially, indicated a transition of SNP predominance from west (G6PD $A-{ }^{968 C}$ polymorphism) to east (G6PD A- ${ }^{202 A}$ widespread and G6PD $A^{968 C}$ apparently absent). However, expansion of the relatively small number of surveys $(\mathrm{n}=20)$ may reveal more complex distributions. Furthermore, the true diversity of G6PD variants cannot be discerned from the assembled surveys; it is not possible to know what proportion of genetic diversity is reflected in the map (Figure 3) because the diagnoses are limited to assessing the presence or absence of a limited number of anticipated SNPs, without any prior identification of phenotypically deficient hosts (as in map series 1). Full gene sequencing is the only reliable way of identifying all gene variants in the population. Genetic diversity within the umbrella G6PD A-phenotype may explain the spectrum of expression levels observed [70]: inheritance of a single SNP may not be sufficient to explain the observed phenotype. If these patterns of co-occurring SNP diversity encoding variable G6PD $A$ - phenotypes are widely observed, a haplotype-based approach which allows for the coinheritance of multiple SNPs may be required if the use of molecular diagnostics is to the scaled-up, as seems to be increasingly common [75]. Despite its obvious limitations to field-based applications, a gene-wide haplotype perspective would also allow increased compatibility with the rapidly expanding human genome sequencing efforts which are cataloguing human genetic diversity $[76,77]$.

Although demand for primaquine has historically been low across Africa [78], it was Ethiopia that reported the highest number of $P$. vivax cases globally in 2011 (665,813 cases; [79]). G6PDd prevalence has been estimated at 1.0\% in Ethiopia (50\% CI: 0.7-1.5) [2], though no molecular information exists to indicate which variants may be responsible. Furthermore, beyond these areas with acknowledged endemic $P$. vivax, the status of transmission in human populations previously considered refractory to infection [78] is being brought into question by several lines of evidence [80-86]. The use of primaquine for $P$. falciparum control may also increase following the new WHO gametocytocide guidelines [63]. The elimination agenda includes African nations, with most located at the fringes of entrenched holo-endemic transmission $[87,88]$, and the pressure to apply primaquine both as a hypnozoitocide for P. vivax and Plasmodium ovale, and as a gametocytocide for $P$. falciparum will increase with further progress towards zero transmission. A more detailed and targeted understanding of African G6PD epidemiology is necessary beyond the opportunistic surveys presented in this paper.

\section{G6PD variants in West Asia}

The G6PD Mediterranean variant, appearing predominant across southwest Asia and exceedingly common in much of India (especially western regions), is known to be highly sensitive to AHA induced by primaquine. This wide distribution and dominance of G6PD Mediterranean presents a significant hurdle to the malaria elimination programmes in West Asia, which include Azerbaijan, Georgia, Iran, Iraq, Kyrgyzstan, Saudi Arabia, Tajikistan, Turkey, and Uzbekistan [89]. These nations must consider the relatively high risk of serious harm caused by unintentional dosing of G6PDd patients in need of malaria therapy. Implementation of G6PDd screening prior to primaquine radical cure therapy would greatly mitigate such risks and accelerate progress to malaria elimination in this region.

Although G6PD Mediterranean was common across Indian populations, two other variants were also frequently reported which were indigenous to populations from this subcontinent: G6PD Kalyan-Kerala and Orissa. Little is known of the primaquine sensitivity phenotypes of these two variants. Since almost half of the global population at risk of $P$. vivax malaria occurs in this single nation $[52,79,90]$ studies characterizing such sensitivity would ultimately prove very useful in planning towards elimination.

\section{G6PD in East Asia and the West Pacific}

The maps of eastern Asia and the western Pacific present the most complex picture of G6PD variants globally, coinciding with regions of heterogeneous and high $P$. vivax endemicity [52]. Almost all the common variants of public health concern globally were reported from this region. Reasons for this genetic diversity are unclear, but it is interesting that $P$. falciparum parasites (postulated to be selective agents of G6PDd [16]) have been found to show a greater degree of population structure with lower genetic relatedness between populations in Asia than across Africa [91]. As well as this overall diversity, the structure of G6PD variant heterogeneity with multiple variants co-occurring is starkly different from other areas where single variants predominate.

Despite large variant diversity across this region where many countries now target elimination (thus require primaquine therapy) [89], only one truly Asian variant has been examined in relation to AHA sensitivity to primaquine. G6PD Mahidol, common across Myanmar and parts of Thailand (Figure 6), exhibits residual G6PD enzyme activity ranging between 5-32\% [42]. A handful of small primaquine sensitivity studies examining this variant have been conducted in Thailand, reporting very 
mild to moderate sensitivity to both 14-day and eight weekly primaquine regimens $[40,92,93]$, as well as to single-dose regimens of $P$. falciparum transmission blocking therapy [94]. However, the G6PD Mahidol primaquine sensitivity phenotype must not be assumed to be representative of the region. As emphasized by the WHO Expert Review Group on primaquine in 2012 $[62,63]$, far greater evidence-based understanding of these phenotypes among the many common Asian variants is urgently needed. The identity and distribution of variants as sensitive as G6PD Mediterranean in the Asia-Pacific region remains unexplored and unknown. This lack of understanding threatens patients and programmes with a more aggressive roll-out of primaquine therapy. In populations of such high heterogeneity, a dual approach of phenotypic screening followed by variant analysis of residual enzyme activity may be required to identify such risks.

The danger of under-diagnosing deficiency by using molecular identification alone (i e, the data informing map series 2) is illustrated by comparison of the two types of maps (Figure $2 \mathrm{C}$ and Additional file 5). If only a selected subset of perceived "common" variants are used in population screening surveys, a proportion of deficient individuals may be missed and put at risk from primaquine therapy: only those variants that are looked for can be identified. The maps presented here also repeatedly highlight considerable proportions of "Other" G6PD variants. These correspond to an unknown haemolytic risk, and hint towards an ever greater diversity of variants. Only full gene sequencing will allow full characterization of the diversity in this polymorphic gene.

\section{Conclusions}

Both the failure to treat $P$. vivax infections and the treatment itself carry some risk of severe clinical complications [5,24,62] (Recht J, Ashley EA, White NJ:8-aminoquinolines safety review for WHO primaquine ERG, unpublished). Each repeated episode of acute $P$. vivax malaria carries possibilities of delayed or improper diagnosis, improper treatment, onward transmission, serious illness, and death [5,24]. Likewise, primaquine-induced AHA in G6PDd patients may provoke renal failure and require multiple transfusions for recovery $[24,43]$. Improper clinical management of primaquine-induced haemolysis may lead to death [24], although the relative risks of this remain poorly documented and are likely to be rare. Similarly, scaled-up application of low-dose transmissionblocking primaquine against $P$. falciparum will likely emerge as a key strategy towards elimination, especially in the context of artemisinin-resistant $P$. falciparum malaria. Evidence-based assessment of the risks incurred with primaquine therapy in any given region is essential for the development of rational strategies to minimize harm caused by either the parasite or the drug used to attack it. The maps presented in this article offer a first glimpse at the distribution of variants of public health significance across malaria-endemic regions. Their implications are discussed with respect to the regionally specific issues associated with the ramping up of primaquine therapy on the strategic road to elimination.

\section{Additional files}

\begin{abstract}
Additional file 1: Supplementary methods.
Additional file 2: Sources from which the datapoints in the maps were identified.

Additional file 3: Map series 2: Americas. Bar charts represent population surveys which examined the frequencies of selected G6PD variants in representative population samples. These population groups had not undergone prior G6PDd phenotype screening. The variants which were tested for in each location are listed above the $x$-axis. Survey locations are indicated by nearby black stars. Sample size is stated under each plot.

Additional file 4: Map series 2: Africa. (A) Bar charts represent population surveys which examined the frequencies of selected G6PD variants in representative population samples. These population groups had not undergone prior G6PDd phenotype screening. The variants which were tested for in each location are listed above the $x$-axis. Sample size is stated under each plot. Survey locations are mapped to closest approximation at the point of origin of the plots; exact survey locations are shown in Panel B. (Panel A is reproduced from Figure 8 in the main manuscript)

Additional file 5: Map series 2: Asia. Bar charts represent population surveys which examined the frequencies of selected G6PD variants in representative population samples. These population groups had not undergone prior G6PDd phenotype screening. The variants which were tested for in each location are listed above the $x$-axis. Survey

locations are indicated by nearby black stars. Sample size is stated under each plot.
\end{abstract}

\section{Abbreviations}

AHA: Acute haemolytic anaemia; CNSHA: Chronic non-spherocytic haemolytic anaemia; G6PDd: Glucose-6-phosphate dehydrogenase deficiency (phenotype); RBC: Red blood cell; SNP: Single nucleotide polymorphism; WHO: World Health Organization.

\section{Competing interests}

The authors declare that they have no competing interests.

\section{Authors' contributions}

$\mathrm{REH}$ conceived the study and oversaw its design and implementation with guidance from FBP, JKB and $\mathrm{SIH}$. REH wrote the first draft of the manuscript, and assembled the data with assistance from MD and WMM. AS, AWS and TNW contributed unpublished data; all authors participated in the interpretation of results and in the writing and editing of the manuscript. All authors read and approved the final manuscript.

\section{Acknowledgements}

We thank Harriet Dalrymple, Suzanne Phillips and Jennie Charlton for help with the library assembly; and to Maria Devine and Kirsten Duda for proofreading. We are grateful to Dennis Shanks for helpful discussions of this work. We also acknowledge the MalariaGen Consortium, particularly Kirk Rockett and Dominic Kwiatkowski. Shivang Shah, Alex Macharia, Carolyne Ndila and Sophie Uyoga are thanked for their help with genotyping. This paper was published with permission from the Director of KEMRI.

This work was supported by a Wellcome Trust Biomedical Resources Grant (\#085406) which funded REH and FBP; SIH is funded by a Senior Research Fellowship from the Wellcome Trust (\#095066) which supports KEB and now also REH; the Oxford University-Li Ka Shing Foundation Global Health 
Programme funds DM; FBP is now funded by the ERC Advanced Grant DIVERSITY (PI: Sunetra Gupta); FAPEAM grant \#062.03140 supports WMM; JPM is funded by the International Research Consortium on Dengue Risk Assessment Management and Surveillance (IDAMS, European Commission 7th Framework Programme (\#21803, http://www.idams.eu); AWS is funded by the Asia Pacific Malaria Elimination Network (APMEN); TNW is funded by the Wellcome Trust (\#091758) and acknowledges support from the MalariaGen consortium; the Wellcome Trust also supports JKB (\#B9RJIXO). This work forms part of the output of the Malaria Atlas Project (MAP, www.map.ox.ac.uk), principally funded by the Wellcome Trust, UK. The funders had no role in study design, data collection and analysis, decision to publish, or preparation of the manuscript.

\section{Author details}

'Spatial Ecology and Epidemiology Group, Department of Zoology, University of Oxford, South Parks Road, Oxford, UK. ${ }^{2}$ Eijkman-Oxford Clinical Research Unit, Jalan Diponegoro No. 69, Jakarta, Indonesia. ${ }^{3}$ Evolutionary Ecology of Infectious Disease Group, Department of Zoology, University of Oxford, South Parks Road, Oxford, UK. ${ }^{4}$ Tropical Medicine Foundation Dr. Heitor Vieira Dourado, Manaus, Amazonas, Brazil. ${ }^{5}$ University of the State of Amazonas, Manaus, Amazonas, Brazil. ${ }^{6}$ Institut Pasteur, Unité de Génétique Fonctionnelle des Maladies Infectieuses, Paris, France. ${ }^{7}$ Eijkman Institute for Molecular Biology, Jakarta, Indonesia. ${ }^{8}$ Kenya Medical Research Institute/ Wellcome Trust Programme, Centre for Geographic Medicine Research-Coast, Kilifi District Hospital, Kilifi, Kenya. ${ }^{9}$ Department of Medicine, Imperial College, St Mary's Hospital, London, UK. ${ }^{10}$ Centre for Tropical Medicine, Nuffield Department of Clinical Medicine, University of Oxford, Oxford, UK.

Received: 5 September 2013 Accepted: 28 October 2013

Published: 15 November 2013

\section{References}

1. Carson PE, Flanagan CL, Ickes CE, Alving AS: Enzymatic deficiency in primaquine-sensitive erythrocytes. Science 1956, 124:484-485.

2. Howes RE, Piel FB, Patil AP, Nyangiri OA, Gething PW, Hogg MM, Battle KE, Padilla CD, Baird JK, Hay SI: G6PD deficiency prevalence and estimates of affected populations in malaria endemic countries: a geostatistical model-based map. PLoS Med 2012, 9:e1001339.

3. The malERA Consultative Group on Diagnoses and Diagnostics: A research agenda for malaria eradication: diagnoses and diagnostics. PLoS Med 2011, 8:e1000396.

4. Baird JK, Surjadjaja C: Consideration of ethics in primaquine therapy against malaria transmission. Trends Parasitol 2011, 27:11-16.

5. Baird JK: Evidence and implications of mortality associated with acute Plasmodium vivax malaria. Clin Microbiol Rev 2013, 26:36-57.

6. Baird JK: Reinventing primaquine for endemic malaria. Expet Opin Emerg Drugs 2012, 17:439-444.

7. White $\mathrm{NJ}$ : The role of anti-malarial drugs in eliminating malaria. Malar $\mathrm{J}$ 2008, 7(Suppl 1):S8.

8. The malERA Consultative Group on Drugs: A research agenda for malaria eradication: drugs. PLoS Med 2011, 8:e1000402.

9. White NJ: Determinants of relapse periodicity in Plasmodium vivax malaria. Malar J 2011, 10:297.

10. Bousema T, Drakeley C: Epidemiology and infectivity of Plasmodium falciparum and Plasmodium vivax gametocytes in relation to malaria control and elimination. Clin Microbiol Rev 2011, 24:377-410.

11. White NJ: Primaquine to prevent transmission of falciparum malaria. Lancet Infect Dis 2012, 13:175-181.

12. WHO: Guidelines for the treatment of malaria, second edition. Geneva: World Health Organization; 2010.

13. WHO: Global plan for artemisinin resistance containment (GPARC). Geneva: WHO; 2011.

14. White NJ, Qiao LG, Qi G, Luzzatto L: Rationale for recommending a lower dose of primaquine as a Plasmodium falciparum gametocytocide in populations where G6PD deficiency is common. Malar J 2012, 11:418.

15. Maude RJ, Socheat D, Nguon C, Saroth P, Dara P, Li G, Song J, Yeung S, Dondorp AM, Day NP, White NJ, White LJ: Optimising strategies for Plasmodium falciparum malaria elimination in Cambodia: primaquine, mass drug administration and artemisinin resistance. PLoS One 2012, 7:e37166.
16. Greene LS: G6PD deficiency as protection against falciparum-malaria: an epidemiologic critique of population and experimental studies. Yearb Phys Anthropol 1993, 36:153-178.

17. Kwiatkowski DP: How malaria has affected the human genome and what human genetics can teach us about malaria. Am J Hum Genet 2005, 77:171-192.

18. Beutler E: G6PD: population genetics and clinical manifestations. Blood Rev 1996, 10:45-52

19. Mueller I, Galinski MR, Baird JK, Carlton JM, Kochar DK, Alonso PL, del Portillo HA: Key gaps in the knowledge of Plasmodium vivax, a neglected human malaria parasite. Lancet Infect Dis 2009, 9:555-566.

20. Cappellini MD, Fiorelli G: Glucose-6-phosphate dehydrogenase deficiency. Lancet 2008, 371:64-74.

21. Howes RE, Battle KE, Satyagraha AW, Baird JK, Hay SI: G6PD deficiency: Global distribution, genetic variants and primaquine therapy. Adv Parasitol 2013, 81:133-201.

22. Murray CJ, Vos T, Lozano R, Naghavi M, Flaxman AD, Michaud C, Ezzati M, Shibuya K, Salomon JA, Abdalla S, Aboyans V, Abraham J, Ackerman I, Aggarwal R, Ahn SY, Ali MK, Alvarado M, Anderson HR, Anderson LM, Andrews KG, Atkinson C, Baddour LM, Bahalim AN, Barker-Collo S, Barrero LH, Bartels DH, Basanez MG, Baxter A, Bell ML, Benjamin EJ, et al: Disabilityadjusted life years (DALYs) for 291 diseases and injuries in 21 regions, 1990-2010: a systematic analysis for the global burden of disease study 2010. Lancet 2012, 380:2197-2223.

23. Lozano R, Naghavi M, Foreman K, Lim S, Shibuya K, Aboyans V, Abraham J, Adair T, Aggarwal R, Ahn SY, Alvarado M, Anderson HR, Anderson LM, Andrews KG, Atkinson C, Baddour LM, Barker-Collo S, Bartels DH, Bell ML, Benjamin EJ, Bennett D, Bhalla K, Bikbov B, Bin Abdulhak A, Birbeck G, Blyth F, Bolliger I, Boufous S, Bucello C, Burch M, et al: Global and regional mortality from 235 causes of death for 20 age groups in 1990 and 2010: a systematic analysis for the global burden of disease study 2010 . Lancet 2012, 380:2095-2128.

24. Lacerda MV, Fragoso SC, Alecrim MG, Alexandre MA, Magalhaes BM, Siqueira AM, Ferreira LC, Araujo JR, Mourao MP, Ferrer M, Castillo P, MartinJaular L, Fernandez-Becerra C, del Portillo H, Ordi J, Alonso PL, Bassat Q: Postmortem characterization of patients with clinical diagnosis of Plasmodium vivax malaria: to what extent does this parasite kill? Clin Infect Dis 2012, 55:e67-e74

25. Luzzatto L: Glucose-6-phosphate dehydrogenase deficiency. In Nathan and Oski's Hematology of Infancy and Childhood. 7th edition. Edited by Orkin SH, Nathan DG, Ginsburg D, Look AT, Fisher DE, Lux SE. Philadelphia: Saunders; 2009.

26. Minucci A, Moradkhani K, Hwang MJ, Zuppi C, Giardina B, Capoluongo E: Glucose-6-phosphate dehydrogenase (G6PD) mutations database: review of the "old" and update of the new mutations. Blood Cells Mol Dis 2012, 48:154-165.

27. Mason PJ, Vulliamy TJ: Glucose-6-phosphate dehydrogenase (G6PD) deficiency: genetics. In Encyclopedia of Life Sciences. Chichester: John Wiley \& Sons, Ltd; 2005.

28. WHO Working Group: Glucose-6-phosphate dehydrogenase deficiency. Bull World Health Organ 1989, 67:601-611.

29. Yoshida A, Beutler E, Motulsky AG: Human glucose-6-phosphate dehydrogenase variants. Bull World Health Organ 1971, 45:243-253.

30. Hockwald RS, Arnold J, Clayman CB, Alving AS: Toxicity of primaquine in Negroes. JAMA 1952, 149:1568-1570.

31. Beutler E: Glucose-6-phosphate dehydrogenase deficiency. N Eng/ J Med 1991, 324:169-174.

32. Dern RJ, Beutler E, Alving AS: The hemolytic effect of primaquine. II. The natural course of the hemolytic anemia and the mechanism of its self-limited character. J Lab Clin Med 1954, 44:171-176.

33. Alving AS, Johnson CF, Tarlov AR, Brewer GJ, Kellermeyer RW, Carson PE: Mitigation of the haemolytic effect of primaquine and enhancement of its action against exoerythrocytic forms of the Chesson strain of Plasmodium vivax by intermittent regimens of drug administration: a preliminary report. Bull World Health Organ 1960, 22:621-631.

34. Cavalli-Sforza LL, Menozzi P, Piazza A: The History and Geography of Human Genes. Princeton, New Jersey: Princeton University Press; 1994.

35. Piomelli S, Corash LM, Davenport DD, Miraglia J, Amorosi EL: In vivo lability of glucose-6-phosphate dehydrogenase in $\mathrm{Gd}^{\mathrm{A}-}$ and $\mathrm{Gd}^{\text {Mediterranean }}$ deficiency. J Clin Invest 1968, 47:940-948. 
36. Meloni T, Forteleoni G, Dore A, Cutillo S: Favism and hemolytic anemia in glucose-6-phosphate dehydrogenase-deficient subjects in North Sardinia. Acta Haematol 1983, 70:83-90

37. Luisada A: Favism. JAMA 1940, 115:632-632.

38. Beutler E, Duparc S: Glucose-6-phosphate dehydrogenase deficiency and antimalarial drug development. Am J Trop Med Hyg 2007, 77:779-789.

39. Clyde DF: Clinical problems associated with the use of primaquine as a tissue schizontocidal and gametocytocidal drug. Bull World Health Organ 1981, 59:391-395.

40. Buchachart K, Krudsood S, Singhasivanon P, Treeprasertsuk S, Phophak N, Srivilairit S, Chalermrut K, Rattanapong Y, Supeeranuntha L, Wilairatana P, Brittenham G, Looareesuwan S: Effect of primaquine standard dose (15 mg/day for 14 days) in the treatment of vivax malaria patients in Thailand. Southeast Asian J Trop Med Public Health 2001, 32:720-726.

41. Matsuoka H, Wang J, Hirai M, Arai M, Yoshida S, Kobayashi T, Jalloh A, Lin K, Kawamoto F: Glucose-6-phosphate dehydrogenase (G6PD) mutations in Myanmar: G6PD Mahidol (487G > A) is the most common variant in the Myanmar population. J Hum Genet 2004, 49:544-547.

42. Louicharoen C, Patin E, Paul R, Nuchprayoon I, Witoonpanich B, Peerapittayamongkol C, Casademont I, Sura T, Laird NM, Singhasivanon P, Quintana-Murci L, Sakuntabhai A: Positively selected G6PD-Mahido mutation reduces Plasmodium vivax density in Southeast Asians. Science 2009, 326:1546-1549.

43. Burgoine $\mathrm{KL}$, Bancone $\mathrm{G}$, Nosten F: The reality of using primaquine. Malar J 2010, 9:376.

44. Laosombat $V$, Sattayasevana B, Chotsampancharoen T, Wongchanchailert M: Glucose-6-phosphate dehydrogenase variants associated with favism in Thai children. Int J Hematol 2006, 83:139-143.

45. Baird JK: Elimination therapy for the endemic malarias. Curr Infect Dis Rep 2012, 14:227-237.

46. Mason PJ, Bautista JM, Gilsanz F: G6PD deficiency: the genotype-phenotype association. Blood Rev 2007, 21:267-283.

47. Mourant AE, Kopec AC, Domaniewska-Sobczak K: The distribution of the human blood groups and other polymorphisms. London: Oxford University Press; 1976.

48. Livingstone FB: Frequencies of hemoglobin variants: thalassemia, the glucose6-phosphate dehydrogenase deficiency, G6PD variants and ovalocytosis in human populations. New York: Oxford University Press; 1985.

49. Nkhoma ET, Poole C, Vannappagari V, Hall SA, Beutler E: The global prevalence of glucose-6-phosphate dehydrogenase deficiency: a systematic review and meta-analysis. Blood Cells Mol Dis 2009, 42:267-278.

50. Singh S: Distribution of certain polymorphic traits in populations of the Indian peninsula and South Asia. Isr J Med Sci 1973, 9:1225-1237.

51. Gething PW, Patil AP, Smith DL, Guerra CA, Elyazar IR, Johnston GL, Tatem AJ, Hay SI: A new world malaria map: Plasmodium falciparum endemicity in 2010. Malar J 2011, 10:378

52. Gething PW, Elyazar IR, Moyes CL, Smith DL, Battle KE, Guerra CA, Patil AP, Tatem AJ, Howes RE, Myers MF, George DB, Horby P, Wertheim HFL, Price RN, Mueller I, Baird JK, Hay SI: A long neglected world malaria map: Plasmodium vivax endemicity in 2010. PLoS Negl Trop Dis 2012, 6:e1814.

53. Hay SI, Guerra CA, Gething PW, Patil AP, Tatem AJ, Noor AM, Kabaria CW, Manh BH, Elyazar IR, Brooker S, Smith DL, Moyeed RA, Snow RW: A world malaria map: Plasmodium falciparum endemicity in 2007. PLoS Med 2009, 6:e1000048

54. Battle KE, Gething PW, Elyazar IR, Moyes CL, Sinka ME, Howes RE, Guerra CA, Price RN, Baird KJ, Hay SI: The global public health significance of Plasmodium vivax. Adv Parasitol 2012, 80:1-111.

55. Hay SI, Guerra CA, Tatem AJ, Noor AM, Snow RW: The global distribution and population at risk of malaria: past, present, and future. Lancet Infect Dis 2004, 4:327-336.

56. Mendis K, Sina BJ, Marchesini P, Carter R: The neglected burden of Plasmodium vivax malaria. Am J Trop Med Hyg 2001, 64:97-106.

57. Singh H, Parakh A, Basu S, Rath B: Plasmodium vivax malaria: is it actually benign? J Infect Pub Health 2011, 4:91-95.

58. Mahgoub H, Gasim Gl, Musa IR, Adam I: Severe Plasmodium vivax malaria among Sudanese children at New Halfa Hospital, Eastern Sudan. Parasit Vectors 2012, 5:154

59. Douglas NM, Nosten F, Ashley EA, Phaiphun L, van Vugt M, Singhasivanon $P$, White NJ, Price RN: Plasmodium vivax recurrence following falciparum and mixed species malaria: risk factors and effect of antimalarial kinetics. Clin Infect Dis 2011, 52:612-620.
60. Harris I, Sharrock WW, Bain LM, Gray KA, Bobogare A, Boaz L, Lilley K, Krause D, Vallely A, Johnson ML, Gatton ML, Shanks GD, Cheng Q: A large proportion of asymptomatic Plasmodium infections with low and sub-microscopic parasite densities in the low transmission setting of Temotu Province, Solomon Islands: challenges for malaria diagnostics in an elimination setting. Malar J 2010, 9:254.

61. Eziefula AC, Gosling R, Hwang J, Hsiang MS, Bousema T, Von Seidlein L, Drakeley C, On behalf of the Primaquine in Africa Discussion Group: Rationale for short course primaquine in Africa to interrupt malaria transmission. Malar J 2012, 11:360.

62. Malaria Policy Advisory Committee Meeting: WHO Evidence Review Group Report: the safety and effectiveness of single dose primaquine as a P falciparum gametocytocide. Geneva: World Health Organization; 2012

63. Global Malaria Programme WHO: Updated WHO Policy Recommendation: Single dose Primaquine as a gametocytocide in Plasmodium falciparum malaria. Geneva: World Health Organization; 2012.

64. Edgcomb JH, Arnold J, Yount EH Jr, Alving AS, Eichelberger L, Jeffery GM, Eyles D, Young MD: Primaquine, SN 13272, a new curative agent in vivax malaria; a preliminary report. J Natl Malar Soc 1950 9:285-292.

65. Alving AS, Hankey DD, Coatney GR, Jones R Jr, Coker WG, Garrison PL, Donovan WN: Korean vivax malaria. II. Curative treatment with pamaquine and primaquine. Am J Trop Med Hyg 1953, 2:970-976.

66. Coatney GR, Alving AS, Jones R Jr, Hankey DD, Robinson DH, Garrison PL, Coker WG, Donovan WN, Di Lorenzo A, Marx RL, Simmons $\mathrm{H}$ : Korean vivax malaria. V. Cure of the infection by primaquine administered during long-term latency. Am J Trop Med Hyg 1953, 2:985-988.

67. Flanagan CL, Schrier SL, Carson PE, Alving AS: The hemolytic effect of primaquine. VIII. The effect of drug administration on parameters of primaquine sensitivity. J Lab Clin Med 1958, 51:600-608.

68. Beutler $\mathrm{E}$ : The hemolytic effect of primaquine and related compounds: a review. Blood 1959, 14:103-139.

69. Alving AS, Craige B, Pullman TN, Whorton CM, Jones R, Eichelberger L: Procedures used at Stateville Penitentiary for the testing of potential antimalarial agents. J Clin Invest 1948, 27:2-5.

70. Shekalaghe SA, ter Braak R, Daou M, Kavishe R, van den Bijllaardt W, van den Bosch S, Koenderink JB, Luty AJ, Whitty CJ, Drakeley C, Sauerwein RW, Bousema T: In Tanzania, hemolysis after a single dose of primaquine coadministered with an artemisinin is not restricted to glucose-6phosphate dehydrogenase-deficient (G6PD A-) individuals. Antimicrob Agents Chemother 2010, 54:1762-1768.

71. Luzzatto $L$ : The rise and fall of the antimalarial Lapdap: a lesson in pharmacogenetics. Lancet 2010, 376:739-741.

72. Pamba A, Richardson ND, Carter N, Duparc S, Premji Z, Tiono AB, Luzzatto L: Clinical spectrum and severity of hemolytic anemia in glucose 6phosphate dehydrogenase-deficient children receiving dapsone. Blood 2012, 120:4123-4133.

73. Galiano S, Gaetani GF, Barabino A, Cottafava F, Zeitlin H, Town M, Luzzatto $L$ : Favism in the African type of glucose-6-phosphate dehydrogenase deficiency (A-). BMJ 1990, 300:236.

74. Mehta AB: Glucose-6-phosphate dehydrogenase deficiency. Postgrad Med J 1994, 70:871-877.

75. Clark TG, Fry AE, Auburn S, Campino S, Diakite M, Green A, Richardson A, Teo YY, Small K, Wilson J, Jallow M, Sisay-Joof F, Pinder M, Sabeti P, Kwiatkowski DP, Rockett KA: Allelic heterogeneity of G6PD deficiency in West Africa and severe malaria susceptibility. Eur J Hum Genet 2009, 17:1080-1085

76. 1000 Genomes - A Deep Catalog of Human Genetic Variation. In. www.1000genomes.org

77. International HapMap Project. In. http://hapmap.ncbi.nlm.nih.gov.

78. Howes RE, Patil AP, Piel FB, Nyangiri OA, Kabaria CW, Gething PW, Zimmerman PA, Barnadas C, Beall CM, Gebremedhin A, Menard D, Williams TN, Weatherall DJ, Hay SI: The global distribution of the Duffy blood group. Nat Commun 2011, 2:266.

79. WHO: World Malaria Report 2012. Geneva: World Health Organization; 2012.

80. Boyd MF: An Introduction to Malariology. Cambridge, MA: Harvard University Press; 1930.

81. Guerra CA, Howes RE, Patil AP, Gething PW, Van Boeckel TP, Temperley WH, Kabaria CW, Tatem AJ, Manh BH, Elyazar IR, Baird JK, Snow RW, Hay SI: The international limits and population at risk of Plasmodium vivax transmission in 2009. PLoS Negl Trop Dis 2010, 4:e774. 
82. Ryan JR, Stoute JA, Amon J, Dunton RF, Mtalib R, Koros J, Owour B, Luckhart S, Wirtz RA, Barnwell JW, Rosenberg R: Evidence for transmission of Plasmodium vivax among a duffy antigen negative population in Western Kenya. Am J Trop Med Hyg 2006, 75:575-581.

83. Culleton R, Ndounga M, Zeyrek FY, Coban C, Casimiro PN, Takeo S, Tsuboi T, Yadava A, Carter R, Tanabe K: Evidence for the transmission of Plasmodium vivax in the Republic of the Congo, West Central Africa. $J$ Infect Dis 2009, 200:1465-1469.

84. Menard D, Barnadas C, Bouchier C, Henry-Halldin C, Gray LR, Ratsimbasoa A, Thonier V, Carod JF, Domarle O, Colin Y, Bertrand O, Picot J, King CL, Grimberg BT, Mercereau-Puijalon O, Zimmerman PA: Plasmodium vivax clinical malaria is commonly observed in duffy-negative malagasy people. Proc Natl Acad Sci USA 2010, 107:5967-5971.

85. Mendes C, Dias F, Figueiredo J, Mora VG, Cano J, De Sousa B, Do Rosario VE, Benito A, Berzosa P, Arez AP: Duffy negative antigen is no longer a barrier to plasmodium vivax-molecular evidences from the African West Coast (Angola and Equatorial Guinea). PLoS Negl Trop Dis 2011, 5:e1192.

86. Wurtz N, Mint Lekweiry K, Bogreau H, Pradines B, Rogier C, Ould Mohamed Salem Boukhary A, Hafid JE, Ould Ahmedou Salem MS, Trape JF, Basco LK, Briolant S: Vivax malaria in mauritania includes infection of a duffynegative individual. Malar J 2011, 10:336.

87. Feachem RG, Phillips AA, Hwang J, Cotter C, Wielgosz B, Greenwood BM, Sabot O, Rodriguez MH, Abeyasinghe RR, Ghebreyesus TA, Snow RW: Shrinking the malaria map: progress and prospects. Lancet 2010, 376:1566-1578.

88. Cotter C, Sturrock HJ, Hsiang MS, Liu J, Phillips AA, Hwang J, Gueye CS, Fullman N, Gosling RD, Feachem RG: The changing epidemiology of malaria elimination: new strategies for new challenges. Lancet 2013, 382(9895):900-911.

89. UCSF Global Health Group and Malaria Atlas Project: Atlas of MalariaEliminating Countries. University of California, San Francisco: The Global Health Group, Global Health Sciences; 2011.

90. Hay SI, Gething PW, Snow RW: India's invisible malaria burden. Lancet 2010, 376:1716-1717.

91. Manske M, Miotto O, Campino S, Auburn S, Almagro-Garcia J, Maslen G, O'Brien J, Djimde A, Doumbo O, Zongo I, Ouedraogo JB, Michon P, Mueller I, Siba P, Nzila A, Borrmann S, Kiara SM, Marsh K, Jiang H, Su XZ, Amaratunga C, Fairhurst R, Socheat D, Nosten F, Imwong M, White NJ, Sanders M, Anastasi E, Alcock D, Drury E, et al: Analysis of Plasmodium falciparum diversity in natural infections by deep sequencing. Nature 2012, 487:375-379.

92. Takeuchi R, Lawpoolsri S, Imwong M, Kobayashi J, Kaewkungwal J, Pukrittayakamee S, Puangsa-art S, Thanyavanich N, Maneeboonyang W, Day NP, Singhasivanon P: Directly-observed therapy (DOT) for the radical 14-day primaquine treatment of Plasmodium vivax malaria on the Thai-Myanmar border. Malar J 2010, 9:308.

93. Myat Phone K, Myint O, Aung N, Aye Lwin H: The use of primaquine in malaria infected patients with red cell glucose-6-phosphate dehydrogenase (G6PD) deficiency in Myanmar. Southeast Asian J Trop Med Public Health 1994, 25:710-713.

94. Song J, Socheat D, Tan B, Dara P, Deng C, Sokunthea S, Seila S, Ou F, Jian H, $\mathrm{Li}$ G: Rapid and effective malaria control in Cambodia through mass administration of artemisinin-piperaquine. Malar J 2010, 9:57.

doi:10.1186/1475-2875-12-418

Cite this article as: Howes et al:: Spatial distribution of G6PD deficiency variants across malaria-endemic regions. Malaria Journal 2013 12:418.

\section{Submit your next manuscript to BioMed Central and take full advantage of:}

- Convenient online submission

- Thorough peer review

- No space constraints or color figure charges

- Immediate publication on acceptance

- Inclusion in PubMed, CAS, Scopus and Google Scholar

- Research which is freely available for redistribution 